\title{
Configurações
}

Revista de sociologia

Violência e Criminalidade

\section{Violência e criminalidade}

Sílvia Gomes, Vera Duarte e Maria João Leote de Carvalho

\section{(2) OpenEdition \\ Journals}

Edição electrónica

URL: http://journals.openedition.org/configuracoes/2837

DOI: 10.4000/configuracoes.2837

ISSN: 2182-7419

\section{Editora}

Centro de Investigação em Ciências Sociais

\section{Edição impressa}

Data de publição: 18 dezembro 2015

Paginação: $7-10$

ISBN: 1646-5075

ISSN: 1646-5075

\section{Refêrencia eletrónica}

Sílvia Gomes, Vera Duarte e Maria João Leote de Carvalho, «Violência e criminalidade », Configurações [Online], 16 | 2015, posto online no dia 29 dezembro 2015, consultado o 22 setembro 2020. URL : http://journals.openedition.org/configuracoes/2837; DOI : https://doi.org/10.4000/configuracoes. 2837 


\title{
Introdução Violência e criminalidade
}

\author{
SÍLVIA GOMES* \\ Universidade do Minho \\ VERA DUARTE** \\ ISMAI e Universidade do Minho \\ MARIA JOÃO LEOTE DE CARVALHO*** \\ CICS.NOVA, Universidade Nova de Lisboa
}

O presente número da revista Configurações pretende contribuir para o estudo da violência e dos seus novos (e velhos) contornos nas sociedades contemporâneas num quadro de globalização. Num tempo marcado por uma violência difusa, disseminada por toda a sociedade, não é por demais reafirmar que, nas suas mais variadas formas e expressões, a violência é uma componente estrutural das dinâmicas sociais. A novas formas do social e a novos agentes e instituições associam-se representações sociais diferenciadas, outros conflitos e processos sociais relativamente aos quais urge a sociologia analisar e reconstruir criticamente (Santos, 2009).

A ideia de que a violência está no horizonte da vida social não é nova (Lourenço, 1991). Contudo, as atuais relações entre direito e sociedade, controlo social e administração da justiça, bem como a multiplicidade das interpretações sobre as mesmas, parecem convergir para a noção de que as práticas de violência são uma linguagem e norma específicas para alguns grupos sociais. A violência emergente em diferentes contextos parece assentar numa espécie de aceitação ou resignação da sociedade, que a incorpora como prática social e política normal e coletiva (Santos, 2009) potenciando a sua reprodução e disseminação.

\footnotetext{
* Doutorada, investigadora de pós-doutoramento no Centro Interdisciplinar de Ciências Sociais, polo Universidade do Minho (CICS.NOVA - polo UM), com uma bolsa de pós-doutoramento financiada pela Fundação para a Ciência e a Tecnologia (FCT), com ref. SFRH/BPD/102758/2014; investigadora da Unidade de Investigação em Criminologia e Ciências do Comportamento (UICCC.ISMAI). Email: silvia. gomes@ics.uminho.pt.

** Doutorada, professora no Instituto Universitário da Maia (ISMAI) e investigadora do Centro Interdisciplinar de Ciências Sociais, polo Universidade do Minho e da Unidade de Investigação em Criminologia e Ciências do Comportamento do Instituto Universitário da Maia (UICCC.ISMAI). Email: vduarte@ismai.pt. *** Doutorada, investigadora do Centro Interdisciplinar de Ciências Sociais - Faculdade de Ciências Sociais e Humanas, Universidade Nova de Lisboa (CICS.NOVA.FCSH/UNL). Email: mjleotec@sapo.pt.
} 
Transversais a todos os grupos sociais, os fenómenos de violência sob a forma de crime, que constituem o foco de análise das pesquisas na origem dos artigos aqui reunidos, geram preocupação social e causam alarme pelos impactos na ordem e coesão sociais. São processos sociais que não podem ser analisados sem ter em consideração as relações de poder entre indivíduos e grupos sociais e a pluralidade de tipos de normas sociais que regem os indivíduos, determinando, em simultâneo, orientações e ações muitas vezes divergentes e conflituantes entre si. Presentes nas mais diversas dimensões da vida social, violência e crime são problemas sociais complexos e polissémicos, que contemplam diferentes configurações e produzem realidades sociais dinâmicas de difícil acesso. A sua análise exige a conjugação de fatores individuais e sociais, económicos, políticos, culturais e outros que, por sua vez, no quadro das profundas mudanças sociais que marcam as sociedades contemporâneas, obrigam também ao questionamento sobre as fronteiras conceptuais da definição do que é violência.

As crianças constituem um dos grupos sociais especialmente vulneráveis à violência. Teresa Castro, António J. Osório e Emma Bond, no artigo apresentado, discutem de que forma é que as crianças veem um tipo específico de crime, a pirataria informática, numa era em que o digital faz parte do seu quotidiano e as transformações tecnológicas são tão intensas. A partir de uma abordagem de natureza participativa, os autores exploram a complexidade da vida digital das crianças e chegam à conclusão de que, entre outros aspetos, a pirataria online é moralmente aceitável entre as crianças e que existe uma preocupante falta de conhecimento e sentido de impunidade relativamente a essas práticas, que ocorrem a qualquer altura e em qualquer lugar. Problematizando os dados obtidos, os autores apontam que antigos e novos vetores de vitimização, vulnerabilidade e dano parecem estar a emergir nestas práticas, nas quais as crianças podem ser simultaneamente agressoras e vítimas. Nesta linha de orientação, os autores defendem que deve ser dada especial atenção a práticas ilegais e desviantes na internet, especialmente em relação às crianças que nelas se envolvem ativamente.

Dando enfoque a um grupo social distinto, Maria João Guia e João Pedroso refletem em torno das eventuais relações existentes entre imigração e crime violento. Não obstante os estudos nesta área demonstrarem, nos últimos anos, a inexistência de uma correlação entre estes dois fenómenos, sendo inclusivamente apontada uma relação inversa em estudos desenvolvidos em contexto norte-americano, os autores debruçam-se sobre a análise destas questões na realidade portuguesa. Verificam que, apenas nos roubos, os migrantes se destacam na curva de aumento de condenações, não sendo, no entanto, os resultados estatística e qualitativamente significativos para concluir haver uma relação significativa neste campo. Assim, o estudo efetuado e aqui apresentado não comprovou a existência de uma relação entre imigração e crime violento no 
território nacional, ainda que destaque que, relativamente ao crime de roubo, existe uma crescente sobrerrepresentação de condenados não nacionais, entre os quais os migrantes correspondem apenas a uma parte.

Ainda sobre o crime violento, mas mudando agora o foco para a realidade brasileira, o terceiro artigo, da autoria de Elaine Pimentel, Henrique Santos, Ana Nunes, Ane Mendes e Juliane Silva, debruça-se sobre os homicídios cometidos contra um dos grupos sociais de maior vulnerabilidade no Brasil: os moradores de rua (designados como sem-abrigo, em Portugal). A partir de uma pesquisa que incide sobre os inquéritos policiais que apuraram esses homicídios, os autores procuram verificar os fatores que dificultaram a resolução dos casos criminais e a responsabilização penal de quem pratica esses crimes. Concluem que existem dois grupos de fatores. Por um lado, a condição de moradores de rua, sem referenciais familiares e sem residência fixa, que acaba por levar a uma dupla vitimação: vitimadas não apenas pelo homicídio em si, mas também pela violência simbólica presente no quotidiano de todos aqueles que não recebem apoio do Estado. Por outro lado, as condições materiais das estruturas de investigação criminal dos homicídios, seja pela degradação de equipamentos e recursos materiais, seja pela escassez de profissionais qualificados para conduzir uma investigação de qualidade.

Sephora Marchesini apresenta-nos uma análise do fenómeno do stalking a partir do estudo dos Acórdãos dos Tribunais da Relação portugueses, em data anterior à sua tipificação como crime. A autora conclui que o termo stalking já era do conhecimento e usado pelos magistrados desde o início da disseminação das investigações científicas nacionais de prevalência sobre o tema, a partir de 2010. Mostra ainda que os casos refletem os resultados dos estudos realizados que associam o stalking aos contextos de relações afetivas, estando próximo do crime de violência doméstica.

Mantendo a tónica nos fatores explicativos de processos de violência e relações violentas em espaços considerados privados, Ana Paula Gil, Ana João Santos, Rita Nicolau e César Santos debruçam-se sobre os fatores de risco associados às condições de ocorrência da violência contra as pessoas idosas em contexto familiar. Com base numa revisão da literatura, os autores identificam os fatores de risco associados a esta população nas últimas décadas, especialmente na Europa e nos países anglo-saxónicos, salientando a existência de um número restrito de casos de violência, diferenciados a partir de amostras de base populacional. Esta diferenciação cria limitações à determinação dos fatores de risco e às metodologias adotadas para a sua estimativa.

Por fim, centrados num assunto pertinente e atual no país, Suzana Caldeira, Osvaldo Silva, Áurea Sousa, Maria José Martins, Maria Mendes e Susana Botelho apresentam os principais resultados de uma pesquisa sobre as perceções dos estudantes do ensino superior relativamente à existência ou não de violência nas praxes académicas e se estas se relacionam com as perceções 
sobre os níveis de satisfação com a vida. Este estudo, quantitativo, mostra que os estudantes apontam as praxes como contendo alguma violência. Mas, como indicam os autores, apesar de alguns estudantes representarem as praxes como um tempo de humilhação e violência, esta perceção não constrange significativamente o sentido e o projeto de vida de cada um. Não obstante estes resultados, os autores alertam para o facto de ser necessário não menosprezar a influência perniciosa de alguns grupos organizados de praxistas e lembram que têm ocorrido situações extremas em anos recentes que levaram à morte de estudantes. Ademais, outros estudos, de cariz qualitativo, sobre as questões da violência nas praxes académicas no ensino superior identificam também algumas manifestações de sexismo, machismo e violência nas praxes, bem como ambivalência na vivência destas práticas e uma divisão entre os estudantes no que respeita às opiniões e modo como vivem a praxe.

Os contributos desta revista evidenciam perspetivas multidisciplinares, partem de contextos geográficos diferenciados, com enfoques e olhares diferentes, mas com uma preocupação comum: trazer à discussão os velhos e os novos contornos da violência e da criminalidade e de como estes fenómenos são palco de reconfigurações sociais.

\section{Referências bibliográficas}

LOURENÇO, N. (org.) (1991). Violência na Sociedade. Lisboa: Contexto.

SANTOS, J. V. T. (2009). Violências e Conflitualidades, Porto Alegre: Tomo Editorial (Série Sociologia das Conflitualidades, 3 ). 